\title{
Modern methods of treatment plant materials for waste minimization
}

\author{
I. A. Pankina ${ }^{1, *}$, E. S. Belokurova ${ }^{1}$, N.A. Politaeva ${ }^{1}$, V. N. Lomasov ${ }^{1}$, N. Z. Bashun ${ }^{2}$ \\ ${ }^{1}$ Peter the Great Saint-Petersburg Polytechnic University 195251 Polytechnicheskaya, 29, St. Petersburg, Russia \\ ${ }^{2}$ Yanka Kupala State University of Grodno
}

\begin{abstract}
Nowadays in the food industry great attention is paid to reducing losses at the stages of agricultural products' harvesting, treatment, and storage. Many developed countries produce food products of extended storage period. To increase the shelf life of semi-finished and finished food products, nonthermal treatment methods are being used that allow one to save a greater amount of biologically active substances. One of these methods is products treatment by ionizing radiation. The article presents the results of assessing the influence of radiation treatment on microbiological, physico-chemical and organoleptic characteristics of vacuumized semi-finished products from potatoes. A technology for the production of semi-finished products using ionizing radiation has been developed, an effective dose of irradiation of vacuumized semi-finished products has been selected, which allows prolonging their shelf life. The research results show the influence of ionizing radiation on the cellular structure of root crops, which soften a little when treated by radiation. The determined quantity of mesophilic aerobic and facultative anaerobic microorganisms shows that ionizing radiation has a microbicidal and microbostatic effect, which allows increasing the shelf life of vacuumized semi-finished products from potatoes.
\end{abstract}

\section{Introduction}

One of the main tasks of the food industry worldwide is to increase the number of manufactured products by reducing waste at all stages of industrial treatment of agricultural raw materials. This can be achieved through the use of innovative and environmentally-friendly technologies [1,2]. At present, much attention is also paid to environmentally-safe technologies for processing household waste and wastewater [3-6].

In order to extend the shelf life and reduce the loss of food products, their special treatment - conservation is used.

The action of preservative factors is aimed at slowing down or stopping enzymatic processes, as well as at suppressing vital functions or destroying microorganisms that cause food spoilage. Conservation methods are divided into physical, chemical, physicochemical, microbiological and biochemical.

Nowadays, the physical methods are increasingly often used in many countries of the world. These include the following methods: ultrasonic sterilization, treatment with high-frequency currents and ultraviolet, radiation treatment, the practice of using a pulsed electric field, ozonation, and others [7-9].

Innovative methods provide higher quality, increase the shelf life of products, and are potentially able to provide better preservation of nutritional value, that is, to make products healthier [8-9]. The literature analysis showed that the use of ionizing radiation to process raw materials is of strategic importance for the development of the global market of health-friendly products. All over the world, it is believed that this technology is one of the most studied safe methods of non-thermal treatment of food products [10-18].

Ionizing radiation is the irradiation that has sufficient energy to separate electrons from atoms or molecules, thereby ionizing them. Raw materials and food products are exposed to ionizing radiation in order to inactivate pathogenic microorganisms, in particular Escherichia coli, Listeria and Salmonella [13, 19-21]. International organizations, namely the United Nations Food and Agriculture Organization (FAO), the World Health Organization (WHO) and the International Atomic Energy Agency (IAEA) guarantee the safety of ionizing radiation use for food treatment in order to obtain food that is safe for health and to preserve their nutritive properties [14,22,23].

Studies of food quality after radiation sterilization have shown the promise of this technique. Today, ionizing radiation is recommended for use to storage of semi-finished products and culinary products, meat, fish and other marine products, potatoes, onions and other root crops, in the spring and summer months, for perishable berries and fruits for the periods of their transportation from producer to consumer, as well as fruit juice concentrates and other agricultural products. The ionizing radiation treatment technology also allows one to control the degree of products infection by insects

\footnotetext{
* Corresponding author: pankina_ia@spbstu.ru
} 
Table 1. Recommended irradiation doses used at radiation treatment of food products.

\begin{tabular}{|l|c|c|}
\hline \multicolumn{1}{|c|}{ Product } & Radiation dose, kGy & The purpose of irradiation \\
\hline Potato, onion & $0.05-0.15$ & Germination inhibition \\
\hline Grain, fruit & $0.15-0.50$ & Pest control \\
\hline Fruits, vegetables & $0.5-1.0$ & $\begin{array}{c}\text { Slowing down of ripening } \\
\text { processes }\end{array}$ \\
\hline Strawberries, vegetables & $1.5-3.0$ & Extending of shelf life \\
\hline Fruit and vegetable products & $1.0-3.0$ & $\begin{array}{c}\text { Decontamination of fruits and } \\
\text { vegetables (4) }\end{array}$ \\
\hline Fresh fruit and vegetable products & $1.0-3.0$ & Mold growth prevention (4) \\
\hline Fresh and frozen chicken, shrimps & $2.0-5.0$ & $\begin{array}{c}\text { Destruction of pathogenic } \\
\text { parasites and microorganisms }\end{array}$ \\
\hline Food products & $2.0-10$ & $\begin{array}{c}\text { Improving the technological } \\
\text { properties of a number of food } \\
\text { products }\end{array}$ \\
\hline Food additives and ingredients (spices) & & Disinfection \\
\hline Meat, meat products, diet products for patients & $30-50$ & Sterilization \\
\hline
\end{tabular}

and parasites, and inhibits the maturation and germination processes.

In accordance with the recommendations of the International Organization for Standardization, the Gray (Gy) is adopted as the unit of measurement of the absorbed dose of ionizing radiation. This is the amount of energy ( $\mathrm{J}$ ) absorbed by $1 \mathrm{~kg}$ of product. The doses absorbed by the products during treatment are measured in $\mathrm{kGy}$. The maximum dose depends on the purpose of product treatment $[15,22]$.

Nowadays treatment of agricultural and food products is carried out in more than 60 countries. Radiation treatment of food products is most effectively used worldwide for the following purposes: pest control, slowing down of ripening and germination, increasing of shelf life, preventing of mold growth, and inactivation of pathogenic microorganisms. Various modes of radiation treatment of food products [13,14,20,24-27] are used depending on the set goals and objectives, Table 1.

The aim of this study was to assess the influence of radiation treatment on the microbiological, physicochemical and organoleptic characteristics of vacuumized semi-finished products from potatoes. The main task was to develop a technology for production of semi-finished products using ionizing radiation, as well as selection of an effective dose of radiation for vacuumized semifinished products in order to extend their shelf life.

\section{Materials and methods}

The raw materials of the Russian production - the Nevsky potatoes (grown in the Leningrad Oblast, Russia) were selected as the object of the study. In this work, we developed a technology for the production of vacuumized semi-finished products using radiation treatment [21].

Research was carried out in several stages. Potato roots of approximately the same size were selected. Then they were washed, inspected, and the greened potato root crops, as well as that damaged by pests and with sympthoms of spoilage were taken away. Then root crops were mechanically peeled. The peeled root crops were packed in $200 \mathrm{~g}$ packages of 100 microns thick PET film (lavsan). Potato samples were vacuumized using the vacuum machine (Grado di protezione: IP-20).

At the next stage of experiment, all samples of semifinished products subjected to evacuation were divided into two parts. The first part of samples was stored in a refrigerator at a temperature of $4 \pm 2{ }^{\circ} \mathrm{C}$ for the entire period of studies. The second part of samples was subjected to radiation treatment using the K-120000 cobalt installation. The exposure time was 60 minutes, and the radiation doses were 2,5 , and $10 \mathrm{kGy}$. The evacuated and irradiated semi-finished products were stored in refrigeration conditions throughout the entire period of studies at the same temperature of $4 \pm 2{ }^{\circ} \mathrm{C}$.

At the third stage, the storage periods of vacuumized semi-finished products were investigated. To determine the shelf life of the treated and untreated root samples, a number of studies were carried out to determine their organoleptic, physico-chemical and microbiological characteristics.

The moisture content and titration acidity were determined from physico-chemical parameters for all samples. The physico-chemical characteristics of potato quality were determined using the standard methods $[28,29]$.

All studies of organoleptic, physico-chemical and microbiological quality indicators of vacuumized vegetables were carried out on the 11th, 18th, 26th, 33rd and 46th days from the beginning of evacuation and radiation treatment.

\section{Results and discussion}

The organoleptic assessment of vacuumized vegetable semi-finished products shows that the sensory characteristics of samples exposed to ionizing radiation compare favourably with the quality indicators of semifinished products that are not exposed to radiation. It was 


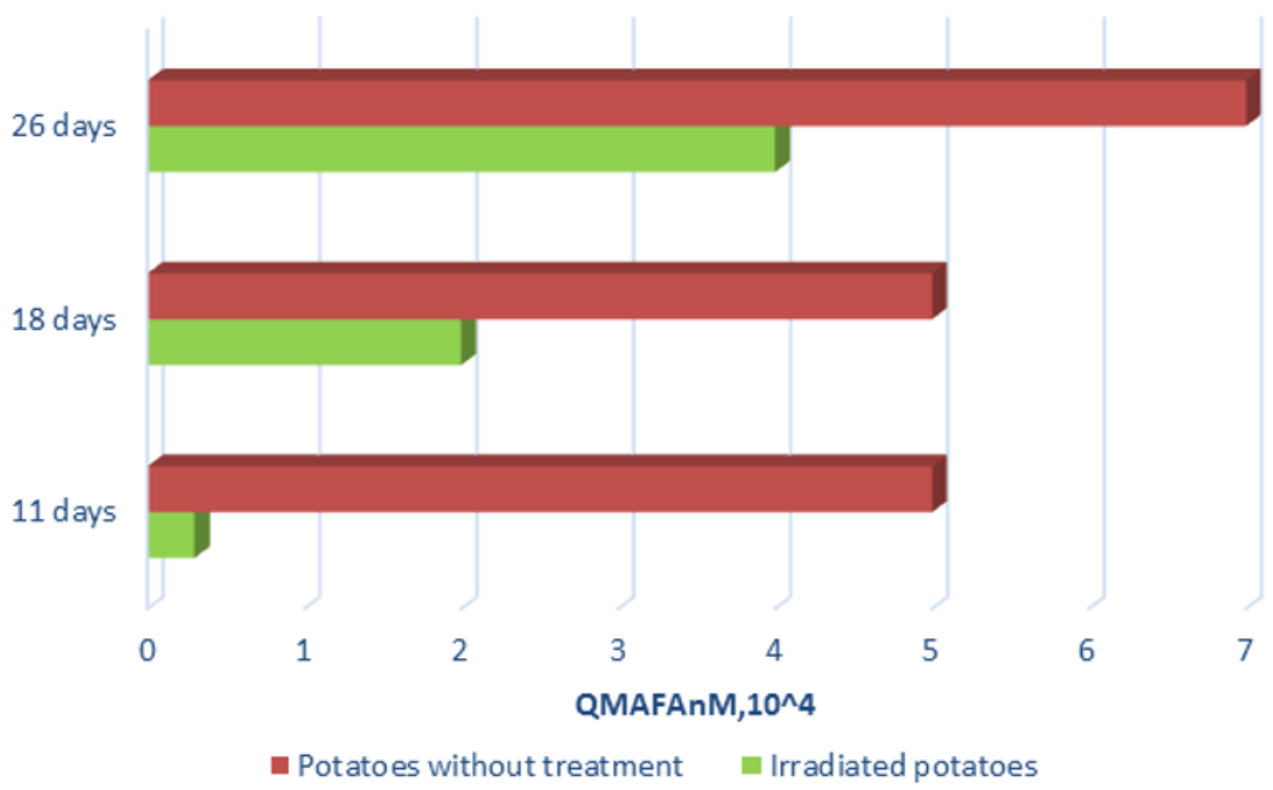

Fig. 1. The QMAFAnM indicator of irradiated and non-treated vegetable semi-finished products.

found that the evacuated samples of root crops that were not exposed to radiation did not withstand long-term storage (33 and 46 days), because they had a significant deterioration of quality indicators, manifested in darkening of samples, softening of their structure, appearance of an extraneous putrefactive odor. These changes, apparently, occurred as a result of microbiological spoilage. Therefore, these samples received very low scores during the tasting assessment; therefore, they did not participate in further studies.

Microbiological spoilage of vegetable products most often begins before the visually observed signs of spoilage appear, therefore, determination of microbiological parameters is very important when conducting research. The determined microbiological parameters of the studied samples are presented in figure.

It is known from literature that efficiency of radiation usage as a method of semi-finished products decontamination depends on the sensitivity of certain types of vegetable products to radiation [20,30,31]. Determination of the quantity of mesophilic aerobic and facultative anaerobic microorganisms (QMAFAnM) on the 11th, 18th, and 26th days after the samples evacuation showed that the semi-finished products subjected to ionizing radiation showed a smaller number of colonies at the time of performing the microbiological studies. The QMAFAnM indicator on the 26th day of storage for vacuumized potatoes treated with irradiation is 1.75 times less than that of untreated potatoes. It means that ionizing radiation has a microbicidal and microbostatic effect, which ensures longer shelf life of the product. The storage time during which the vegetable semi-finished products remained safe according to microbiological indicators was not more than 11 days for untreated vacuumized semi-finished products, and 26 days for those treated with radiation.

\section{Conclusions}

Modern technologies cannot guarantee production of fresh fruit and vegetable products completely free of pathogens throughout the entire storage period. According to experts, about $25 \%$ of raw materials are lost due to microbiological spoilage and insect contamination after harvest. Therefore, effective measures must be included in the systems for production and sale of fresh fruits and vegetables to ensure the products safety for the health of consumers. At present, this safety can be ensured at a high level using technologies for treatment of raw materials and finished products with ionizing radiation.

The sensory evaluation of vacuumized semi-finished products showed that radiation treatment of vegetables (with doses up to $10 \mathrm{kGy}$ ) doesn't cause significant changes in their commercial quality, but in some cultures, cell juice is released. During prolonged storage, the total score of the organoleptic evaluation of samples decreases. It is important to note that for samples of treated foods, the total score is higher than that of untreated ones. The results of organoleptic studies correlate with the results of determining microbiological parameters. So, in samples not subjected to ionizing radiation, an unpleasant odor was observed, indicating signs of semi-finished products' damage. Thus, ionizing radiation reduces the microbiological contamination of vegetables, and this allows one to increase the shelf life of the vacuumized vegetable products.

The storage time during which the vegetable semifinished products remained safe according to microbiological indicators was not more than 11 days for untreated vacuumized semi-finished products, and 26 days for those treated with radiation. 
The results of the study allow us to suggest that the radiation treatment of vegetable products, as non-thermal method, can be used to increase the shelf life of vacuumized semi-finished products. The most appropriate dose for potato irradiation is $10 \mathrm{kGy}$, since these samples retained consumer properties for the longest time.

\section{References}

1 J. Bazarnova, J. Sepiashvili, V. Gnilitsky, and A. Grebenyuk (2018). Combined technologies for food preservation using biological barriers. Proceedings of universities applied chemistry and biotechnology. 8. pp. 166-173. (2018)

2. N. Zhilinskaia, J. Bazarnova, A. Shleikin, L. Peshuk and O. Galenko Using of bioinformatics and computer morphometry in study of Fusarium spp. causing potato dry rot. (Ukrainian Food Journal. V.5, iss.3. 2016) pp. 515-522

3. A. Chusov., V. Maslikov, D. Molodtsov and V. Korablev. Organization of Organic Waste Samples Tests for Biogas Potential Assessment. International Scientific Conference Energy Management of Municipal Facilities and Sustainable Energy Technologies EMMFT 2018, pp.440-448

4. M. Shilin, V. Abramov, O. Mandryka, A. Ershova, and A. Chusov. Environment survey of northwest Russia population health. International Multidisciplinary Scientific GeoConference Surveying Geology and Mining Ecology Management, SGEM. 2019.

5. A. Chusov, V. Maslikov, D. Molodtsov and O. Manukhina A. Determination of environmental impact factors of flood control hydrosystems with temporarily filled self-regulating reservoirs. (Advances in Intelligent Systems and Computing. volume. 692. 2018) pp. 10461054.

6. E. Bondarenko, Kh. Il'ina, M. Andrianova, A. ChusovMain inorganic ions and electric conductivity of polluted urban streams .(Civil engineering journal. No. 8 (68). 2016) pp. 37-44.

7. Innovative technologies of fruit and vegetable products processing / S. Rodriguez, F. A. N. FernandezPer. S eng. under water. ed. Bazarnova Yu. G. - St. Petersburg.: Profession, 2014. - 456 PP.

8. I. Eichholz, S. Huyskens-Keil, A. Keller, D. Ulrich, L. Kroh and S. Rohn. UV-B-induced changes of volatile metabolites and phenolic compounds in blueberries Vaccinium corymbosum L. Food Chemistry, , 126, (2011) p. 60-64.

9. V. Balasubramaniam, D. Farkas and E. Turek. Preserving foods through high - pressure processing // J. of Food Science, 2008, 62, p. 32-38.

10. D. Lisovskaya, L. Galun and G. Mityurich. Radiology of food products: studies. no. under the General editorship of D. P. Lisovskaya. (Committee on the Chernobyl disaster at the SM RB. Gomel: UO BTEU PK, 2003) pp. 296

11. M. Ashokkumar, D. Sunartio, S. Kentish, R. Mawson, L. Simons, K. Vilkhu and C.Versteeg Modification of food ingredients by ultrasound to improve functionality: A preliminary study on a model system. Innovative Food Science and Emerging Technologies, 2008, 9, p. 155-160.

12. E. Zhilyakov, O. Golubeva. Influence of ozoneair treatment on food products. Modern high technology. - 2008. - No. 10. p. 82.

13. Electronic Irradiation of Foods: An Introduction to the Technology. NY: Springer, 2005.

14. M. Moreno, E. Castell-Perez M., C. Gomes, P. Da Silva, and R. Moreira. The effects of electron beam irradiation on physical, textural and micro structural properties of Tommy Atkins Mangoes (Mangifera indica L.). J. of Food Science, 2006, 71(2), p. E80-E86.

15. V. Karpaty. Radiation chemistry of polysaccharides. IV. Free radical mechanisms of education formaldehyde. Chemistry of high energies. 2006. T. 40. No. 1. pp. 18-20.

16. Enhancement of efficiency of storage and processing of food raw materials using radiation technologies / A. Gracheova, M. Zaviyalov, N. Iluhina et al. Nuclear physics . 2016. Vol. 79, no. 14. pp. 1-6.

17. Fabiana Lima, Kássia Vieira, Miriam Santos and Poliana Mendes de Souza (November 5th 2018). Effects of Radiation Technologies on Food Nutritional Quality, Descriptive Food Science, Antonio Valero Díaz and Rosa María García-Gimeno, IntechOpen.

18. Pal M, M. Devrani Application of Various Techniques for Meat Preservation. J Exp Food Chem 4: (2018) p. 134

19. J. Kamenik, A. Salakova, Z. Pavlik, et al. Vacuum skin packaging and its effect on selected properties of beef and pork meat.( European Food Research and Technology, vol. 239, no. 3, 2014), pp. 395-402

20. K. Bialka, A. Demirci Decontamination of 13. Escherichia coli O157:H7 and Salmonella enterica on blueberries using ozone and pulsed UV-light J. of Food Science. 72, p. 2007. pp. 391-396.

21. Using accelerated electron beams for the radiation processing of foodstuffs and biomaterials. A. Alimov, B. Ishkhanov, V. Shvedunov, D. Yurov, U. Bliznyuk, P. Borchegovskaya, S. Varzar, S. Elansky, A. Nikolaeva, V. Rozanov, F. Studenikin, A. Chernyaev, U. Litvinov and I. Matveychuk. (Bulletin of the Russian Academy of Sciences: Physics.. volume. 81. № 6. 2017) pp. 743-747.

22. Standard for Irradiated Foods and Recommended International Code of Practice for the Operation of Radiation Facilities used for the Treatment of Foods / Codex Alimentarius Commission. CAC (Rome), Vol XV, 1984 Ed. 1.

23. Roberts PB. Food irradiation is safe: Half a century of studies. Radiat Phys Chem, 105 (2014) 78

24. Study of irradiated potato starch. V. Litvyak, V. Moscow and E. Koptelova et al. Achievements of science and technology of agroindustrial complex (Moscow) no. 12.(2013) pp. 77-81.

25. K. Korotchenko, V. Karpaty. About the mechanism of formation of dicarboxylic acids in corn starch at irradiation in the presence of oxygen. (Chemistry of high energies.volume 27. no. 4. 1993) pp. 50-55. 
26Continuous-wave electron linear accelerators for industrial applications. D. Yurov, A. Alimov, B. Ishkhanov, V. Shvedunov. Physical Review Accelerators and Beams. (volume. 20. no. 4. 2017) p. 044702.

27. An investigation of the effects of x-ray treatment on the concentration of reducing sugars in potatos and their sprouting. V. Avdyukhina, U. Bliznyuk, P. Borschegovskaya, A. Buslenko, A. Ilyushin, G. Krusanov., I. Levin, F. Studenikin, A. Chernyaev, E. Kondratieva and A. Sinitsyn. Moscow University Physics Bulletin. (volume 73, no. 3. 2018) pp. 334-338.

28. I. Pankina, A. Khazh Yahya Chernykh Investigation of physical and chemical properties of potato tubers in order to creation of vacuumed semifinished products. Materials of the IV all-Russian scientific conference " Innovations in technologies of healthy food products" (V international. Balt. Sea forum., Kaliningr. state tech. UN-t-Kaliningrad: Publishing house FGBOU IN "KSTU". 2017) pp. 68-74.

29. Measuring methods of control indicators of the quality and safety of food products. A. Vitovtov and other - in 2 h. H. 1: products of plant origin. (SPb.: Ed. "Trinity bridge", 2009). pp. 304.

30. Using accelerated electron beams for the radiation processing of foodstuffs and biomaterials. A. Alimov, U. Bliznyuk, P. Borchegovskaya et al. (Bulletin of the Russian Academy of Sciences: Physics. volume. 81/ no. 6. 2017) pp. 743-747.

31. M. Eltawil, D. Samuel and O. Singhal. Potato Storage Technology and Store Design Aspects\&quot; Agricultural Engineering International: the CIGR Ejournal. Invited Overview No. 11. Vol. VIII. April, 2006. 